Document downloaded from:

http://hdl.handle.net/10251/160675

This paper must be cited as:

Cabrera Rochera, E.; Estruch-Juan, ME.; Gomez Selles, E.; Del Teso-March, R. (2019). Defining complementary tools to the IVI. The Infrastructure Degradation Index (IDI) and the Infrastructure Histogram (HI). Urban Water Journal. 16(5):343-352. https://doi.org/10.1080/1573062X.2019.1669195

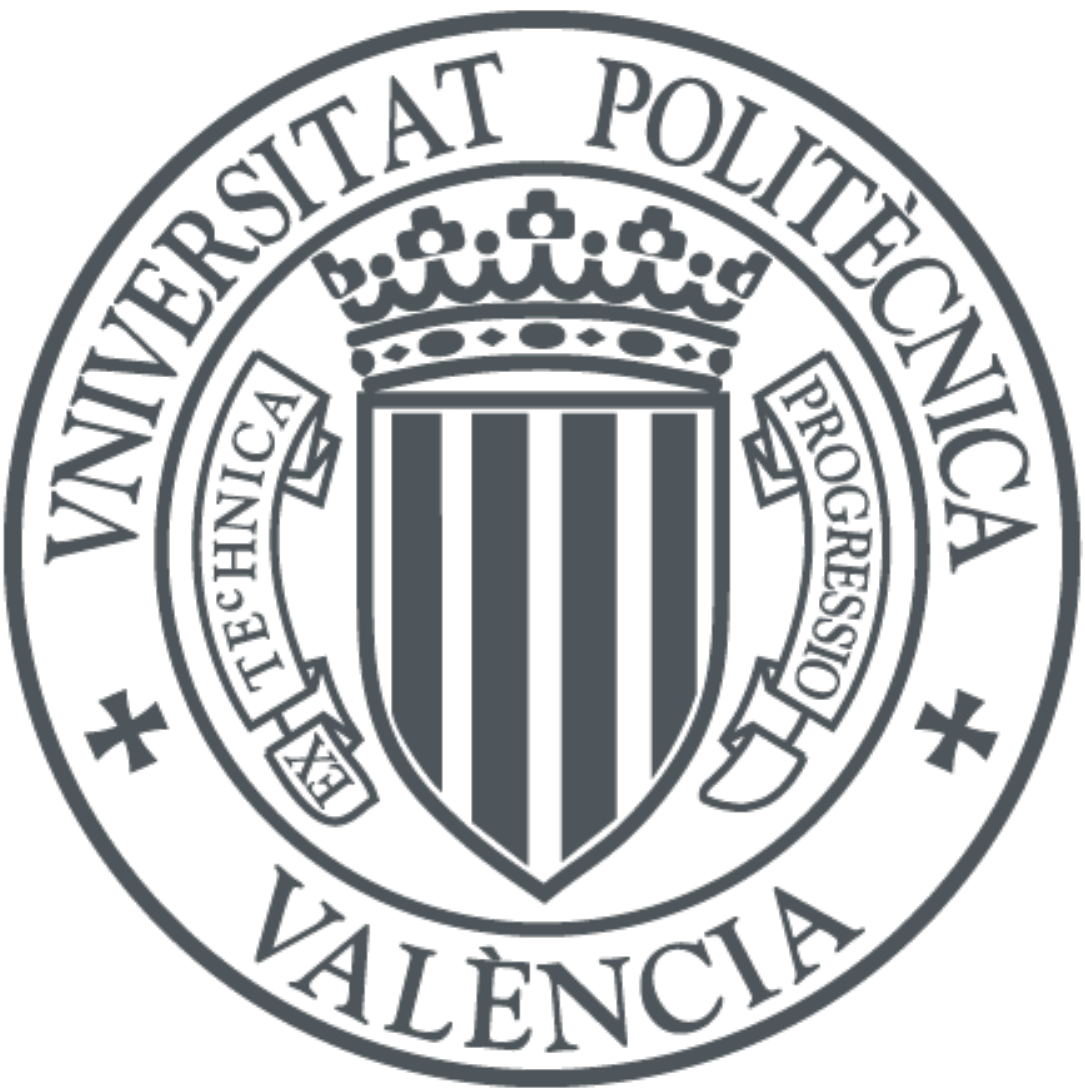

The final publication is available at

https://doi.org/10.1080/1573062X.2019.1669195

Copyright Taylor \& Francis

Additional Information 
Defining complementary tools to the IVI. The Infrastructure

Degradation Index (IDI) and the Infrastructure Histogram $\left(\mathrm{H}_{\mathrm{I}}\right)$

E. Cabrera Jr. ${ }^{\text {a, }}$ E. Estruch-Juan ${ }^{\text {a }}$, E. Gómez ${ }^{\mathrm{a}}$, R. del Teso ${ }^{\mathrm{a}}$

${ }^{a}$ ITA, Universitat Politècnica de València, Camino de Vera s/n, 46022, Valencia, Spain

*Corresponding author: maesjua1@ita.upv.es (Elvira Estruch-Juan) 


\title{
Defining complementary tools to the IVI. The Infrastructure Degradation Index (IDI) and the Infrastructure Histogram $\left(\mathrm{H}_{\mathrm{I}}\right)$
}

\author{
The Infrastructure Value Index (IVI) is quickly becoming a standard as a \\ valuable tool to quickly assess the state of urban water infrastructure. However, \\ its simple nature (as a single metric) can mask some valuable information and \\ lead to erroneous conclusions. This paper introduces two complementary tools to \\ IVI: The Infrastructure Degradation Index (IDI) and the Infrastructure Histogram \\ $\left(\mathrm{H}_{\mathrm{I}}\right)$. The IDI is focused on time (compared to the IVI, focused on value), \\ represents an intuitive concept and behaves in a linear way. The joint analysis of \\ IVI and IDI provides results in a more complete understanding of the state of the \\ assets, while maintaining the simplicity of the tools. The Infrastructure Histogram \\ allows for a full evaluation of the infrastructure state and provides a detailed \\ picture of network age compared to its expected life, as well as an order of \\ magnitude of the required investments in the following years.
}

Keywords: Strategic asset management; water services; rehabilitation; long-term planning, Infrastructure Value Index, renovation

\section{Introduction}

Water infrastructures are capital intensive, are designed for a long operational life (Alegre and Covas 2010; Baptista 2014) and it is not uncommon to find systems in which reactive renovation policies have been applied and where the replacement rate has been very low over extended periods of time. Additionally, urban water infrastructures are mostly buried, increasing their rehabilitation costs and lowering the awareness of stakeholders about their state (AWWA 2012).

As a consequence, users are not aware of the elevated capital costs associated to water services and the investments needed to maintain them, as they did not pay for them nor remember when infrastructures were installed (AWWA 2001). In addition, 
investment in rehabilitation of networks is often low, as tariffs usually do not cover total costs (Cabrera Jr. 2016; Pulido-Veláquez, Cabrera, and Garrido 2014).

The state of water infrastructures is becoming a global concern as they are ageing without being sufficiently substituted or rehabilitated. According to a study undertaken by Frost \& Sullivan (2011), 40\% of European water networks are in need of rehabilitation. In the US, an ASCE report disclosed that in 2010, the water sector needed investments totalling US\$ 55,000 million (ASCE 2011). This amount was expected to increase to 84,000 million by 2020 and to 144,000 million by 2040 . In New Zealand, $25 \%$ of the network length is over 50 years old and between 10 and $20 \%$ of the infrastructures require renewal or are unserviceable (CSA 2014). The need to adequately maintain and renew water services' assets is undeniable, as the integrity of many infrastructures is at risk (GWRC 2009) and so is the sustainability of the services provided with them.

Utility managers, regulators, environmental agencies and academics have become increasingly interested in finding suitable solutions to this problem. Since the first asset management plans, applied in the mid-eighties in Australia and New Zealand (van Heck 2008), asset management practices have been growing in the water sector. Examples of this increased interest are the Asset Management ISO 55000 standards (ISO, 2014a, 2014b, 2014c) and manuals of reference such as: the "International Infrastructure Management Manual (IIMM)” (IPWEA 2015); “The National Guide to Sustainable Municipal Infrastructure" (Boudreau and Brynildsen 2003) or the "Guidelines and manuals of best practice for an integrated planning for a Sustainable UWC management" developed under the EU Funded TRUST Project (Alegre and Covas 2015; Alegre, Brito, and Covas 2015; Almeida, Covas and Beceiro 2015; Nottarp-heim et al. 2015). 
Getting started in the management of infrastructure assets is not easy, as IAM plans depend on the context of the utility and need a personalised process (Leitão et al. 2016). Besides, a significant amount of data needs to be collected in order to make informed decisions. Obtaining such data is a resource and time-consuming activity, and utilities facing IAM for the first time highlight the lack of data as one of the key difficulties they find in the early stages (Rokstad, Ugarelli, and Sægrov 2016). And yet, at these early stages, decision makers find it useful to obtain an estimation of the overall state of the assets and how urgent is their renovation.

The Infrastructure Value Index (IVI) (Alegre 2008) is a simple measure that reflects the rehabilitation needs of an infrastructure and can be considered an effective communication tool to portray its state (Alegre, Vitorino, and Coelho 2014).

The IVI is relatively easy to calculate and although it is quite recent, it has already been adopted by a significant number of utilities. In Portugal, the water, wastewater and waste regulator (ERSAR) annually assesses the state of the infrastructures with this index. In Spain, IVI is starting to be widely used by the sector and the Spanish Water Utilities Association (AEAS) has included it as a key assessment tool in their new IAM manual of best practices (AEAS, forthcoming). The inclusion of IVI as a component of software suites has extended its use. For instance, IVI is included in the free AWARE-P software (Aware-p.org, 2014). Consequently, it has been used by more than 2000 registered users in over 100 countries around the world (see Figure 1). The Baseform software suite (Baseform, 2018) also includes IVI, and the index is currently in use by utilities in Israel, Australia, USA, Brazil, Chile, Portugal, Spain and Canada.

While IVI is a very intuitive indicator and can provide a birds-eye view of the state of the infrastructure in a system, it lacks sufficient depth and detail to evaluate 
investment needs or prioritize such investments. It should be considered as an entrylevel tool to raise awareness on the situation of water networks and as a very effective communication tool for stakeholders like the administration or consumers.

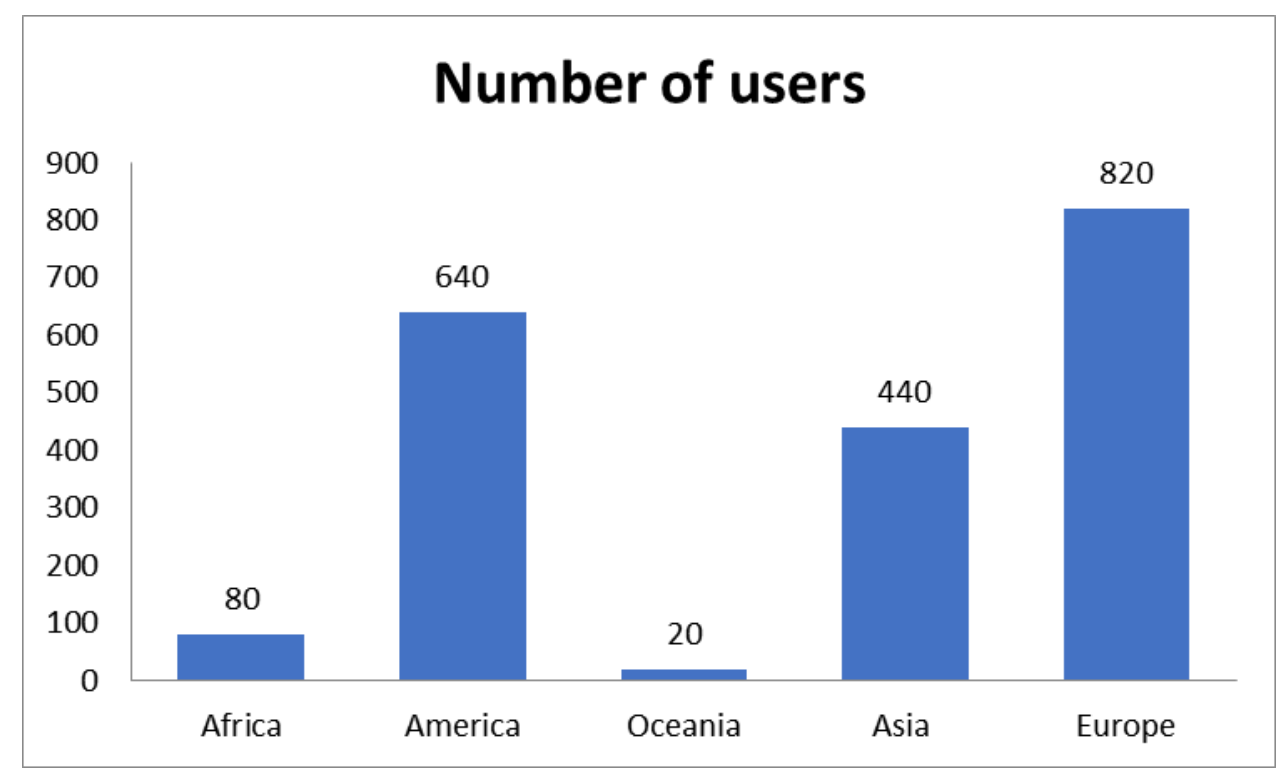

Figure 1. Geographical distribution of Aware-P software users making use of the IVI (AWARE-P users' database).

Given the increasing importance of the IVI as an international standard, a greater understanding of the tool seems necessary. Additionally, while the simplicity of IVI is one of its greatest strengths, it also implies a quite shallow analysis.

This paper will analyse the strengths and weaknesses of the IVI as a basic indicator and present two new complementary tools to allow for a more comprehensive assessment of the state of the infrastructure in a network, while preserving the advantages and simplicity of IVI. Additionally, a case study will be presented and its results analysed and discussed before conclusions are drawn. 


\section{The Infrastructure Value Index as a tool for Infrastructure Asset Management}

IVI is a measure that shows the degree of youth, maturity or aging of an infrastructure. It expresses the ratio between the current value and the replacement value of the infrastructure as seen in equation (1) (Alegre and Covas 2010):

$$
I V I=\frac{\text { Infrastrucutre current value }}{\text { Infrastructure replacement cost }}
$$

The infrastructure replacement value is the cost the infrastructure would have if it were installed brand new, with the same characteristics (Alegre and Covas 2010). The infrastructure current value corresponds to its current price in a competitive market.

The actual IVI formula is presented in equation (2).

$$
I V I(t)=\frac{\sum_{i=1}^{N}\left(r c_{i, t} \times r u l_{i, t} / e u l_{i}\right)}{\sum_{i=1}^{N} r c_{i, t}}
$$

Where:

$\mathrm{t}$ is the reference year when the index is calculated; $\mathrm{N}$ is the total number of assets considered; $\mathrm{rc}_{\mathrm{i}, \mathrm{t}}$ is the cost of the asset $\mathrm{i}$ in the year $\mathrm{t}, \mathrm{rul}_{\mathrm{i}, \mathrm{t}}$ is the residual useful life of asset $i$ in the year t. eul $\mathrm{i}_{\mathrm{i}, \mathrm{i}}$ is the expected useful life of asset $\mathrm{i}$.

Generally, the cost used in the denominator of equation (2) corresponds to the cost the asset would have if installed completely new, while maintaining the same characteristics (material, diameter, etc.); in the year the IVI is calculated.

IVI assesses the infrastructure value for a single year. If the replacement costs and useful life of all the assets in an infrastructure were identical, IVI would represent the infrastructure residual life. In general, IVI can be seen as the weighted average of the residual lives of the infrastructure components weighted by their costs (Alegre, Vitorino, and Coelho 2014).

IVI values range between 0 and 1 . An IVI of 0 means that the infrastructure does not have any value left. A value of 1 represents a completely new infrastructure. Ideally, 
IVI values for a mature and well-maintained infrastructure should range between 0.4 and 0.6. Values over 0.6 correspond to new infrastructures, old infrastructures in a growing phase or over-invested infrastructures. Values lower than 0.4 point to old infrastructures with urgent need of rehabilitation (Alegre and Covas 2010).

Calculating the IVI may not be as straightforward as it seems, even with available data. The aim of the index is to assess the current value of the assets, trying to determine their depreciation. Theoretically, this should be calculated using the original costs at the installation date. However, the authors (Alegre, Vitorino, and Coelho 2014) acknowledge the difficulties associated with this approach (fundamentally lack of data and time specific market fluctuations) and propose to use the current cost of each replacement pipe (knowing it might be cheaper, more expensive or even the material could be unavailable).

This approach also creates a conceptual conflict in the case of utilities that have a well-defined renovation policy, for the actual materials to be used when substituting old pipes are well defined (depending on their diameter, maximum pressure requirements, etc). Furthermore, some pipes are not even replaced, but rather renovated using trenchless methods (for instance in historical city centres, environmentally protected areas, etc.). As an example, Figure 2 displays the standard materials used for pipe renovation, depending on the pipe diameter, for Madrid, Spain (Canal de Isabel II Gestión 2012). 


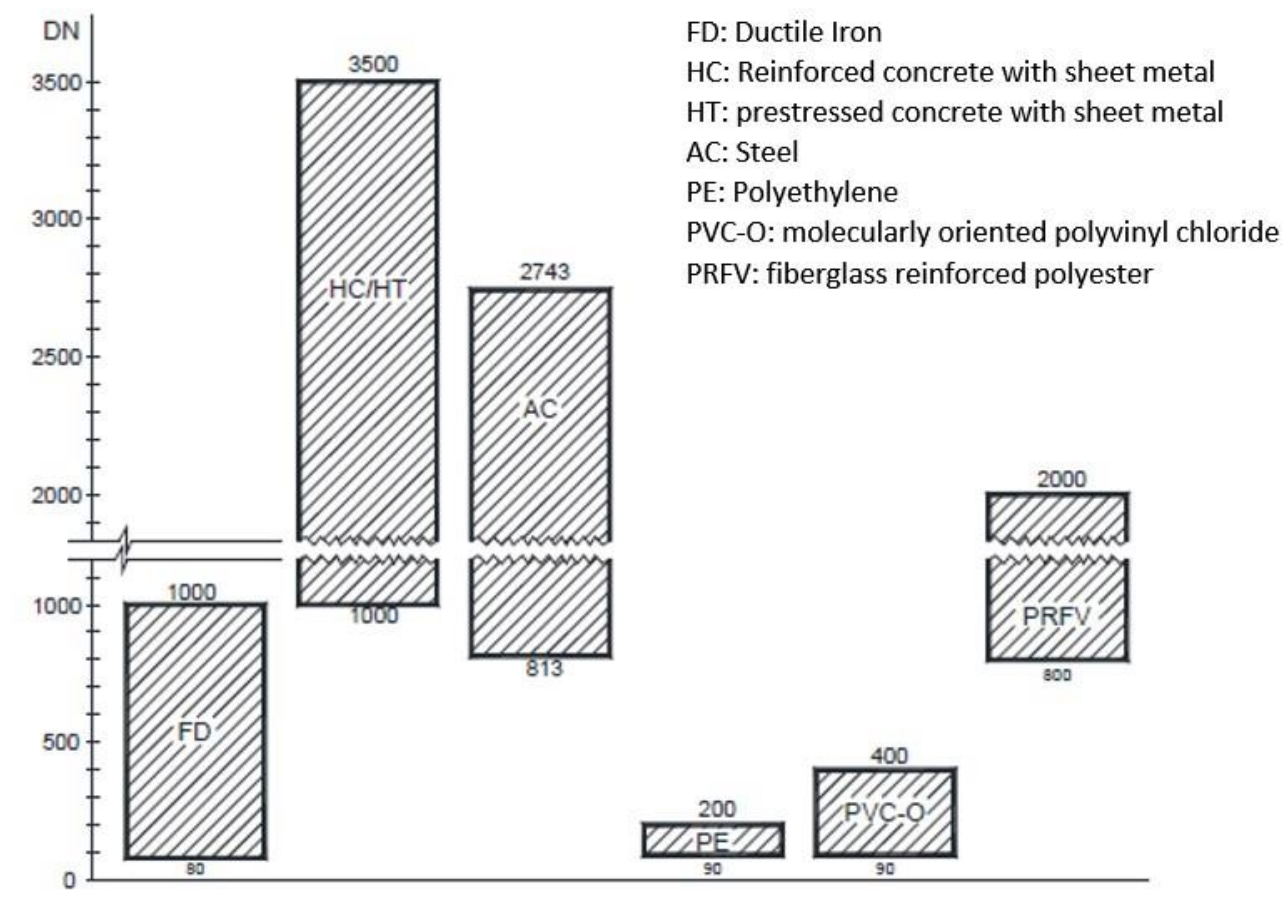

Figure 2: Standard materials used for pipe renovation by nominal diameter (DN in $\mathrm{mm}$ ) - Madrid (Spain) - Canal de Isabel II - Adapted

If such a policy is available, IVI could be calculated using the current costs of the foreseen renovation option, shifting the original IVI "depreciation focus" into an “investment focus".

Calculating the IVI presents some additional challenges:

On one hand, life expectancy for a pipe depends on its material, diameter, soil characteristics, working conditions, etc. It is recommended that this value is estimated from historic registers of failures and the characteristics of each pipe. However, in the absence of significant data, a proxy value can be obtained from the literature (AEASAGA 2017, ISO 2016, AEAS forthcoming, Covas et al. 2018).

On the other hand, as stated by Alegre, Vitorino and Coelho (2014) and Amaral, Alegre and Matos (2016), estimating the useful life of an asset cannot be done without significant uncertainty, as assets may decline in their working capacity but they may remain able to provide a service after they have expired (with a lower quality of 
service). This creates a contradiction, as pipes having exceeded their useful life, often remain "in service". The relevance of the actual IVI value as a decision-making tool, will strongly depend on the life expectancy of each asset.

Additionally, the exact total cost for the replacement of each asset is difficult to estimate, as it should include items such as the removal of the existent asset, the cost of the new asset, personnel costs, machinery, etc. Recent literature provides insight on how to calculate these costs for urban water and wastewater systems in Portuguese utilities (Marchionni et al. 2015; Marchionni et al. 2014). In addition, the Portuguese regulator ERSAR is developing a technical guide to summarize the cost of construction of urban water infrastructures in Portugal (Covas et al. 2018); including a web application where infrastructure costs can be easily calculated. However, these cost models have been developed for Portugal, and a similar work may be necessary for each region or country.

The information presented by IVI represents a snapshot of the state of the network at a moment in time. However, this single metric may not be enough to fully assess the condition of the network. This paper presents two tools, complementary to IVI, that provide additional information about the state of the infrastructure and contribute to improve the decision-making process, while maintaining the simple and intuitive nature of IVI.

\section{Infrastructure Degradation Index (IDI)}

The Infrastructure Degradation Index (IDI) aims to complement the information provided by the IVI, while preserving its simplicity and communication effectiveness. The need for such a complementary analysis is illustrated by showing how decision makers could be misled if using only IVI values when managing their assets.

For instance, two hypothetical systems with identical IVI value (0.5) could present very 
different situations in terms of future investment:

System 1 , with a fixed $2 \%$ replacement rate throughout its history, and all assets with a lifecycle of 100 years, would keep a constant $50 \%$ average valuation of its assets $(\mathrm{IVI}=0.5)$

System 2, would represent an extreme case where $50 \%$ of its network has already aged beyond its expected life (100 years), and therefore has no residual value, while the other $50 \%$ has just been replaced in the current year. Therefore, the average residual value of System 2 would also be $50 \%$ of its total replacement costs, with an $\mathrm{IVI}=0.5$.

It is obvious that the reality of both networks is completely different and so should be the strategies to manage their assets. Even though this example is almost impossible to find in real life, it clearly illustrates that the IVI cannot be the only source of information to be considered when assessing water network assets.

The IDI expresses the average remaining age of the network weighted by length and can be calculated as follows:

$$
\text { Infrastructure Degradation Index }(t)=\frac{\sum_{i=1}^{N} L_{i, t} \times r u l_{i, t}}{\sum_{i=1}^{N} L_{i, t}}
$$

Where:

$\mathrm{t}$ is the reference year when the index is calculated; $\mathrm{N}$ is the total number of pipes considered; $\mathrm{L}_{i, t}$ is the length of the pipe $\mathrm{i}$ in the year $\mathrm{t}, \mathrm{rul}_{\mathrm{i}, \mathrm{t}}$ is the residual life of the pipe $\mathrm{i}$ in the year $\mathrm{t}$. If a pipe has expired its life, $\mathrm{rul}_{\mathrm{i}, \mathrm{t}}$ will be negative and will account for the amount of time the residual life of the pipe has been exceeded.

The IDI is expressed in years and provides a sense of urgency in network renovation. Somehow, the IDI expresses how close a network is (in years) to a hypothetical total collapse date, when, in average, all its pipes have expired. In contrast, the IVI is more focused on investment needs. 
IDI, similarly to IVI, works with averages and therefore has difficulties assessing non-homogeneous cases. However, since the negative value of pipe life is not capped, IDI values will continue to degrade with time in the absence of renovation efforts. Consequently, IDI values can be either positive or negative. The IDI value would reach a maximum in a completely new network.

Recommended values of IDI for an average, well-maintained network, correspond to a 50\% average life remaining for the assets, indicating a balanced asset management strategy. An order of magnitude would be represented by values around the 30 years mark, but acceptable values could be higher or lower, always dependant on the actual materials used in the network and their life expectancy.

If IDI is equal to zero, this means that the average weighted residual life of the network is zero. A low or even negative IDI can be possible with new pipes installed in the network; this would mean that their positive value is being compensated by pipes that already passed their expiry date. This situation is not recommended as it implies that the renovation needs, at least in part of the network, are urgent and cannot be postponed. In this situation, not renewing the network can significantly affect its sustainability and the quality of service.

IDI should not be considered as the only indicator of the degradation state of assets. Other factors can influence such degradation, and age (IDI) does not provide enough information to be conclusive about an assets' state. However, IDI can create awareness, it is a simple proxy to the general condition of network assets and complements IVI while maintaining simplicity.

IDI and IVI might appear to be very similar at first. However, a few key factors differentiate them and turn them into complementary metrics. IVI is a ratio, dimensionless, and expresses the magnitude of investment needs (or depreciation of the 
assets, depending on the approach used as described above). IDI is measured in years, expressing a sense of urgency and how many years are left before a "doomsday" scenario is reached in terms of infrastructure (facilitating communication to nontechnical stakeholders, as a countdown in years is a concept easier to understand).

IDI is linear, and in the absence of investment expresses the number of years that it will take its value to reach zero, with its value decreasing exactly by the time spanned since its previous assessment. Once it reaches a zero value it will move onto negative values maintaining the same rate of change.

IVI on the other hand behaves in a more asymptotic manner, and although it will eventually reach zero, the amount its value decreases every year is reduced as it gets closer to zero. This makes IVI more sensitive to changes when its value is closer to 1 , a characteristic that needs to be considered when it is monitored for changes.

This is the consequence of how IVI values the assets, assigning them a value of zero once the assets have expired. Therefore, in the absence of renovations, the amount of assets subtracting value from the index is reduced year after year (while in IDI, as they increase their negative value, they maintain their influence). This is why the IVI is unable to assess if a percentage of the length of the network expired 2 or 20 years ago.

Figure 3 illustrates the linearity in the sensitivity of IDI vs the IVI. The graph on the left (1) shows how the values of IDI evolve with time, with a fixed descending slope. The slope of IVI values, on the contrary, tends to diminish and reduce its sensitivity with time (an equal rate of change in the infrastructure age will produce smaller changes of IVI as years go by). The graph on the right (2) shows the time evolution of the slope of both indices further illustrating this effect. 


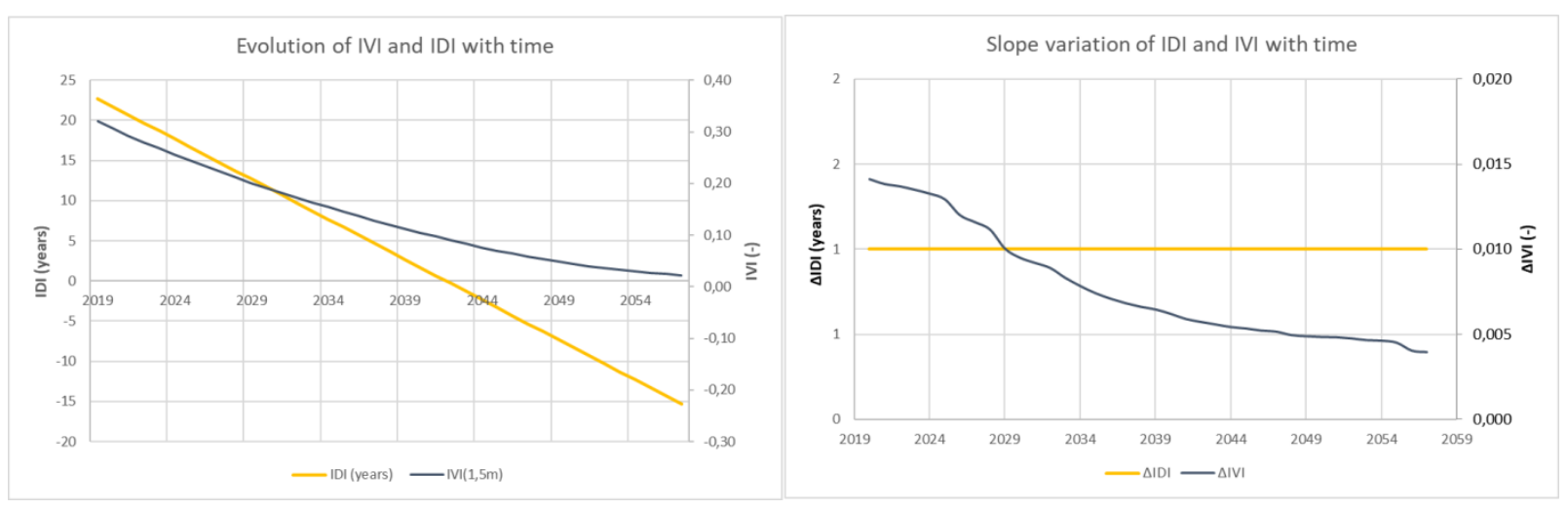

Figure 3. (1) Evolution of IVI and IDI with time. (2) Slope variation of IDI and IVI with time. Analysis of network 8, (Table 3) from 2019 to 2057, considering no renovation is undertaken in the network

The following example aims to illustrate the differences between the two indices (and the need to use them simultaneously to achieve a fuller picture). Table 1 shows three identical networks, differing only in the year in which the different pipes were installed. However, all pipes share the same characteristics (material, diameter, length...).

Table 1. IVI and IDI values of Networks 1, 2 and 3. Values calculated for year 2019

\begin{tabular}{|l|l|l|l|}
\hline & Network 1 & Network 2 & Network 3 \\
\hline $\begin{array}{l}\text { Year of installation (45\% of the network } \\
\text { length) }\end{array}$ & 1967 & 1942 & 1994 \\
\hline $\begin{array}{l}\text { Year of installation (55\% of the network } \\
\text { length) }\end{array}$ & 2012 & 2012 & 1994 \\
\hline IVI & 0.5 & 0.5 & 0.5 \\
\hline IDI (years) & 23 & 12 & 25 \\
\hline
\end{tabular}

For the purpose of this example, the expected life of pipes is considered to be 50 years. Therefore, $45 \%$ of all pipes installed in networks 1 and 2 have already expired at the year of analysis (2019). Despite the obvious differences, all three IVI values are identical. All pipes installed before 1969 do not influence the IVI value as their expected life has expired. 
Furthermore, the third network, built in a single year (1994), also shares the same IVI of 0.5. Considering the IVI value alone, all three networks could be considered to be in an ideal situation.

Their IDI value, as can be seen in the table, is different for all three networks as this index also considers the age of pipes that have aged beyond their expected life.

IDI (like all one-figure metrics) is not perfect, and while networks 1 and 3 present similar values of IVI and IDI, their situation is still dramatically different. However, as the example shows, the combination of IVI + IDI significantly improves the assessment of IVI alone. In any case, the use of the Infrastructure Histogram $\left(\mathrm{H}_{\mathrm{I}}\right)$ is recommended to gain a complete assessment of the situation.

In any case, both IVI and IDI should be considered simple tools to be used at a preliminary stage. Whether used for a quick assessment of potential degradation of the network, or to raise awareness for stakeholders like the public administration or users, they should never replace an in-depth analysis of all factors related to the actual state of the assets and their capacity to provide the service (including the quality of such service).

\section{The Infrastructure histogram $\left(\mathrm{H}_{\mathrm{I}}\right)$}

Despite all the efforts in creating intuitive and representative metrics of the state of a network, one or two numbers cannot possibly account for all the different circumstances of real networks and display them at a glance. The combined use of IVI and IDI represents a solid starting point in the assessment of a network. The next step in a deeper analysis would be the assessment of its Infrastructure Histogram $\left(\mathrm{H}_{\mathrm{I}}\right)$. The $\mathrm{H}_{\mathrm{I}}$ provides detailed information on the aging of the infrastructure in a simple and intuitive way, giving a clear idea of the renovation needs. 
The histogram displays the percentage (in length) of pipes in the network classified by their remaining life. For each pipe the remaining life is calculated as: Remaining life= life expectancy -age.

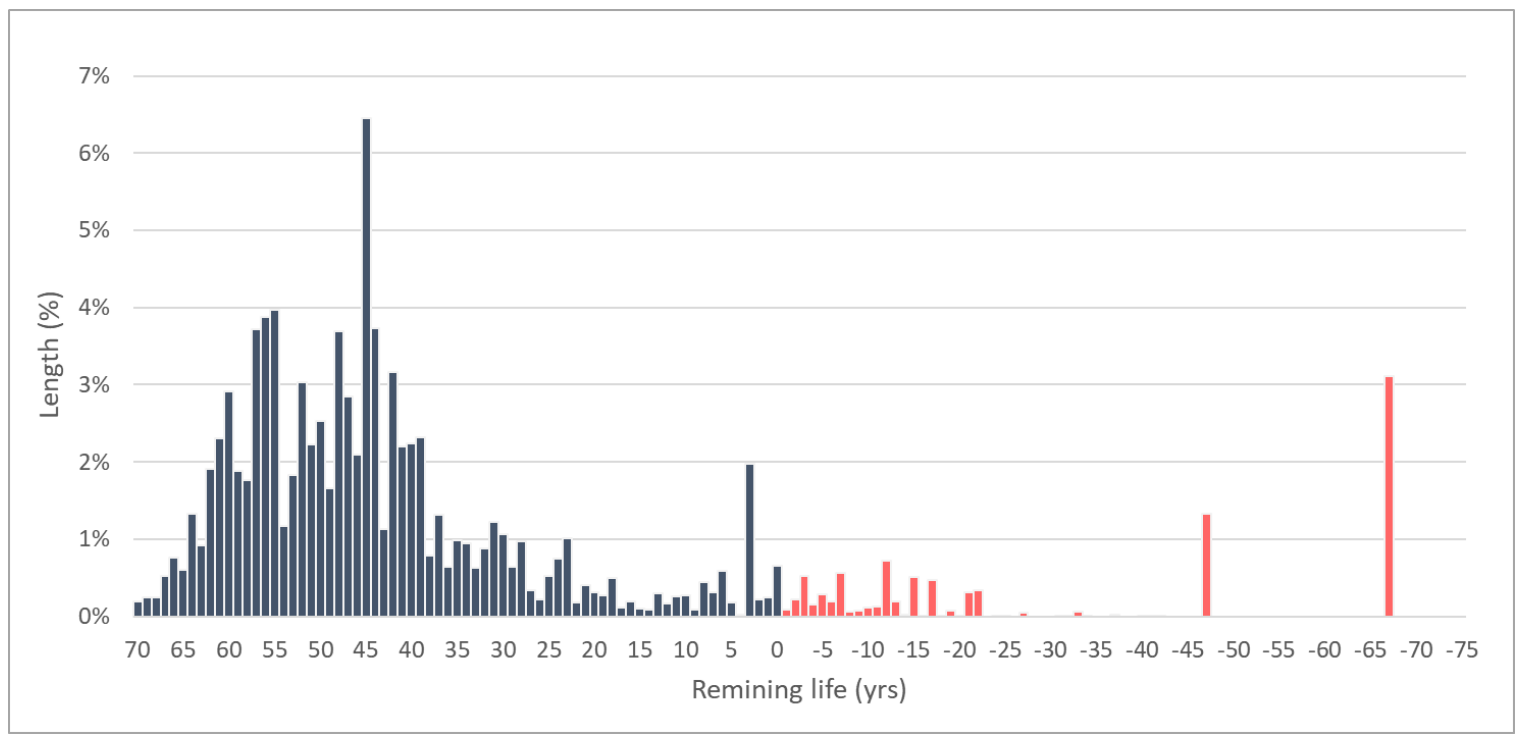

Figure 4. Example of a histogram for a water supply network

Figure 4 shows the $\mathrm{H}_{\mathrm{I}}$ of a network. The black bars on the left belong to pipes with positive remaining life. The red bars on the right correspond to pipes that have aged beyond their expected life (the magnitude of the negative value is the amount of years over the expiry date).

The $\mathrm{H}_{\mathrm{I}}$ is a simple visual aid aimed to facilitate the assessment of network infrastructure. Paired with IVI and IDI values, it provides a very clear picture of the situation of the assets.

Peaks in the $\mathrm{H}_{I}$ denote high investment periods where a significant length of the network was built or renovated. Other peaks may also point in the direction of data uncertainty (for instance, the network in Figure 4 has 3\% of the network with nearly -70 years, probably a sign that the same age was allocated to all unknown pipes present in the network in an initial inventory effort). Therefore, $\mathrm{H}_{\mathrm{I}}$ is also helpful to identify these 
data gaps and to suggest some caution when using such information to identify investment needs.

Figure 5 displays the histogram of Networks 1 and 3 presented in Table 1.

Despite being very simple histograms (due to the synthetic and simplified nature of the example), they allow to easily assess the differences in networks that share values for both IVI and IDI.

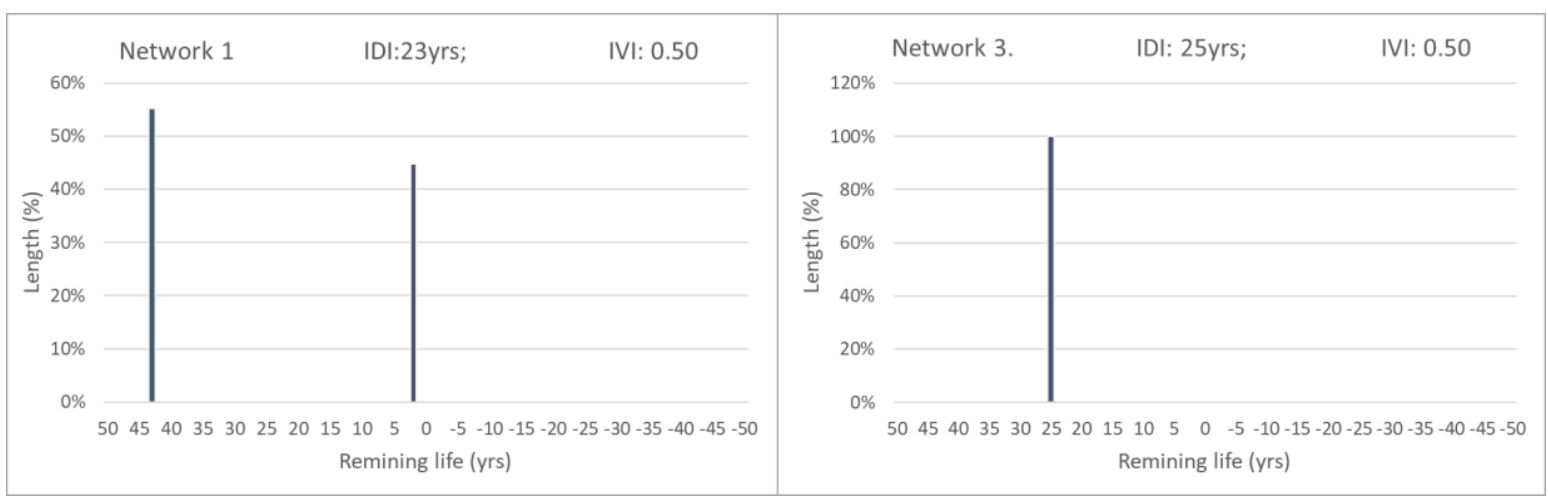

Figure 5. Histogram of Networks 1 and 3 presented in Table 1

Ideally, a flat $\mathrm{H}_{\mathrm{I}}$ would be the sign of a perfectly managed network. Such a histogram would represent a network with a constant renovation rate in length. In contrast, histograms with significant spikes would indicate that future renovation will need considerable investments and disruptions over a short period of time (with the need of long-term planning for the funding) or non-optimum renovation strategies spread in time (either replacing the pipes before their expected life is over or after the pipes have expired).

The location of different areas in the $\mathrm{H}_{\mathrm{I}}$ and their distance from the zero value are of great significance in the analysis of the histogram. To some extent, large areas to the left of the zero value (considering the distance) would increase both IVI and IDI. Areas to the right of the zero value would decrease the IDI value as a function of their distance; however, once they are right of zero, their influence in the IVI value is none. 
A good exercise when analysing the histograms is to think in terms of moment of inertia, where mass (or area, i.e. percentage of network) times the distance (years) is the relevant parameter to assess the global state of the network.

\section{Case study: Use and interpretation of IDI and $\mathrm{H}_{\mathrm{I}}$}

The tools described in the previous chapter were tested in 8 real networks. The anonymous data used to test the IDI and $\mathrm{H}_{\mathrm{I}}$ were provided by Baseform and correspond to actual records of water utilities in developed countries.

Table 2 Life expectancy and percentage of materials used in the case study networks

\begin{tabular}{|c|c|c|c|c|c|c|}
\hline & $\begin{array}{l}\text { Ductile } \\
\text { iron }\end{array}$ & $\begin{array}{l}\text { Asbestos } \\
\text { Cement }\end{array}$ & $\begin{array}{c}\text { Polyethylene } \\
\text { (PE) }\end{array}$ & $\begin{array}{c}\text { Polyvinylchloride } \\
\text { (PVC) }\end{array}$ & Steel & Concrete \\
\hline $\begin{array}{l}\text { Life } \\
\text { expectancy }\end{array}$ & 70 & 50 & 50 & 50 & 70 & 70 \\
\hline Network 1 & $70 \%$ & $7 \%$ & $20 \%$ & $0 \%$ & $1 \%$ & $3 \%$ \\
\hline Network 2 & $46 \%$ & $35 \%$ & $20 \%$ & $3 \%$ & $0 \%$ & $0 \%$ \\
\hline Network 3 & $3 \%$ & $20 \%$ & $45 \%$ & $30 \%$ & $2 \%$ & $0 \%$ \\
\hline Network 4 & $5 \%$ & $9 \%$ & $50 \%$ & $35 \%$ & $1 \%$ & $0 \%$ \\
\hline Network 5 & $1 \%$ & $42 \%$ & $54 \%$ & $1 \%$ & $2 \%$ & $0 \%$ \\
\hline Network 6 & $37 \%$ & $5 \%$ & $52 \%$ & $1 \%$ & $3 \%$ & $2 \%$ \\
\hline Network 7 & $95 \%$ & $0 \%$ & $5 \%$ & $0 \%$ & $0 \%$ & $0 \%$ \\
\hline Network 8 & $55 \%$ & $33 \%$ & $0 \%$ & $0 \%$ & $2 \%$ & $9 \%$ \\
\hline
\end{tabular}

It is always recommended to obtain life expectancy values from historic records of failures and working conditions of assets, as estimations will be far more accurate. However, in the absence of such data (utilities were anonymous) life expectancy for each material was estimated using reference values from the literature (AEAS-AGA 
2017, ISO 2016, AEAS forthcoming). The conclusions obtained in this paper regarding the analytic capabilities of the proposed tools are not in any way affected by changes in these values.

Table 2 shows the estimated life expectancy and proportion in each network for each material.

\section{Results and analysis}

Table 3 presents the IVI and IDI results obtained for each network.

Table 3: IDI and IVI results for each network

\begin{tabular}{|c|c|c|}
\hline & IDI (years) & IVI \\
\hline Network 1 & 37.00 & 0.57 \\
\hline Network 2 & 38.23 & 0.64 \\
\hline Network 3 & 26.57 & 0.51 \\
\hline Network 4 & 30.76 & 0.58 \\
\hline Network 5 & 16.34 & 0.34 \\
\hline Network 6 & 34.04 & 0.52 \\
\hline Network 7 & 22.69 & 0.32 \\
\hline Network 8 & 19.68 & 0.35 \\
\hline
\end{tabular}

Those networks with IVI values in the desired interval (between 0.40 and 0.60 ) have IDI values in the range of well-maintained networks, between 20 and 40 years, (networks 1, 2, 3, 4 and 6). Those with IVI values outside the recommended range are paired with the lowest IDI values (networks 5, 7 and 8).

As shown in the previous examples, there is no clear association between both indices, and similar values of IDI may present significant differences in IVI and vice 
versa. This is a clear indication that both indices are targeting different concepts and that the simultaneous analysis of both values can provide further insight on the actual state of the network. The Infrastructure Histograms (Figure 6) help to complement this initial analysis..

Table 4 presents 5 side-by-side comparisons of networks, where either the IDI or IVI values are similar (shaded cells). In these cases, the value of the complementary indicator (in bold) will help to further assess which network presents a more desirable situation. In the last case, the values of IDI and IVI are inconclusive, as they are all quite similar and network 7 has a better IDI but worse IVI and vice versa. In this case, the $\mathrm{H}_{\mathrm{I}}$ is critical to compare their situation.

Table 4: Comparison of similar networks

\begin{tabular}{|c|c|c|c|}
\hline & IDI (years) & IVI & $\begin{array}{c}\text { Preferred } \\
\text { network }\end{array}$ \\
\hline Network 1 & 37.00 & 0.57 & \\
\hline Network 2 & 38.23 & $\mathbf{0 . 6 4}$ & $\mathbf{X}$ \\
\hline Network 1 & $\mathbf{3 7 . 0 0}$ & 0.57 & $\mathbf{X}$ \\
\hline Network 4 & 30.76 & 0.58 & \\
\hline Network 3 & 26.57 & 0.51 & \\
\hline Network 6 & $\mathbf{3 4 . 0 4}$ & 0.52 & $\mathbf{X}$ \\
\hline Network 5 & 16.34 & 0.34 & \\
\hline Network 7 & $\mathbf{2 2 . 6 9}$ & 0.32 & X \\
\hline Network 7 & $\mathbf{2 2 . 6 9}$ & 0.32 & $?$ \\
\hline Network 8 & $\mathbf{1 9 . 6 8}$ & 0.35 & $?$ \\
\hline
\end{tabular}




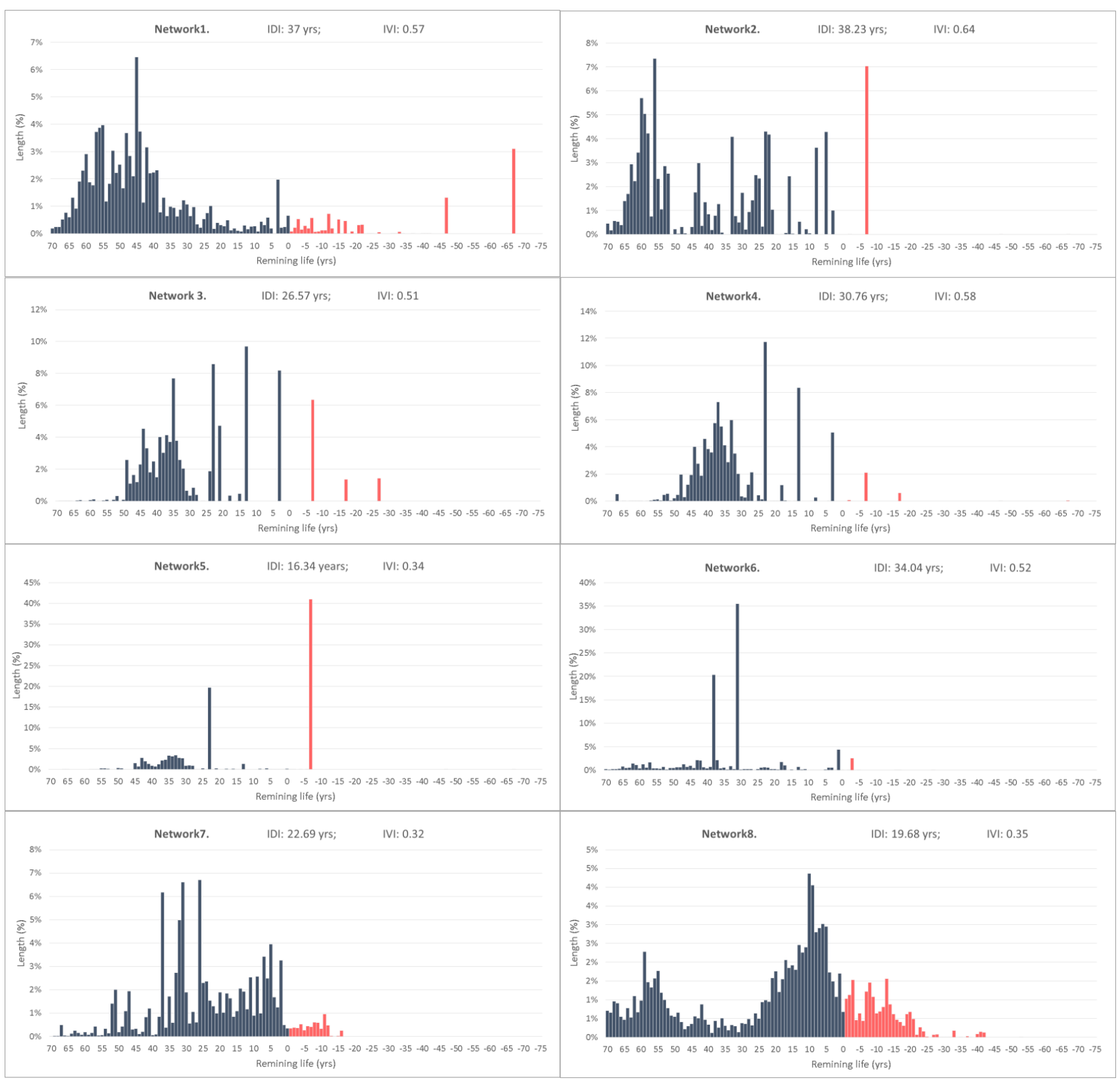

Figure 6. Histogram for the 8 case study networks

\section{Networks 1 and 2}

Networks 1 and 2 have similar IDIs. While the IVI value of Network 1 is in the desired range, Network 2 is slightly over the maximum recommended value (0.6). Both networks present investment peaks (having renewed over 6-7\% of the network at some stage), but the renovation in network 1 is better distributed in time. 
Almost $10 \%$ of Network 1 length has exceeded its expected life. And $4.5 \%$ of those pipes exceeded their expected life more than 40 years ago. Network 2 state is less concerning by far, although $7 \%$ of the network length expired 7 years ago, and an additional $5 \%$ is to expire in less than 5 years.

Therefore, although a high IVI could indicate that Network 2 is in good health, the histogram shows that it may require some immediate action on the short term. Its situation, as suggested in Table 4, is better than Network 1.

\section{Networks 1 and 4}

Networks 1 and 4 have an almost identical IVI (0.57 and 0.58) but their IDIs are more than 6 years apart (37.00 and 30.76). In this case, the materials used in the networks are the origin of the differences in the IDI. As seen in Table 2, Network 1 is mostly laid out with ductile iron, whereas plastic materials (with a shorter life expectancy) are predominant in Network 4.

Considering the histograms, network 1 has a relative advantage despite the fact that it has more expired pipes, as this fact is compensated by the larger life expectancy of the materials used in the network and the significant length of pipes with over 40 years of expected life.

\section{Networks 3 and 6}

These networks have a similar IVI value, 0.51 and 0.52 . However, the IDI of Network 6 is almost 8 year higher the IDI of Network 3 (26.57 vs. 34.04). As in the previous case, Network 6 is built with materials with a longer life expectancy than Network 3 .

This is a good example in which a quick look at the histogram can provide significant insight in addition to the indices. Network 6 has two peaks of construction of 
$20 \%$ and $35 \%$ with 37 and 31 years respectively of remaining life. This will present challenges in the future when their renovation is due.

In any case, a greater portion of Network 3 has its life expectancy expired compared to Network 6. This is a good example where IDI is able to point out a difference in expired assets despite an almost identical IVI.

\section{Networks 5 and 7}

Both networks present similar IVI values $(0.34$ and 0.32$)$ under the recommended value of 0.45 . However, their IDI values are 6 years apart (16.34 and 22.69 respectively).

A quick look to their $\mathrm{H}_{\mathrm{I}}$ (Figure 6) allows concluding that Network 5 disadvantage is due to having a large peak (40\%) of expired pipes. The positive peak of $20 \%$ with a remaining life of 25 years contributes to improve the IVI value.

Network 7 is a network with a history of constant renovation/maintenance. However, a significant mass of pipes in the histogram is close to the zero value (on both sides of the zero). This implies the need for a significant renovation effort in the near future to improve the network's state, and hence the low IVI value.

Therefore, although Network 7 has a low IVI value, the situation is not as critical as in Network 5 because the network will expire gradually, allowing for an easier renovation strategy avoiding peaks of investment. In Network 5 however, there is an urgent need to renovate the $40 \%$ of the network that expired more than 5 years ago.

\section{Networks 7 and 8}

This last example shows the importance of the histogram. While IVI and IDI values are not that different and their comparison may be inconclusive (Table 4) on the short term, Network 7 is in better shape. 
Additionally, the low IVI value in both networks might be misleading. The explanation lies in the materials used. Both networks were mainly built with materials with a long-life expectancy. Since IVI is calculated as a cost-based ratio between the remaining life and the expected life, although both networks still have 20 years left in average, their IVI value is low (as the denominator is quite large, with a life-expectancy of 70 years).

Network 7 will be easier to manage in the short term, although Network 8 may present an advantage in the future if the situation with the large percentage of pipes around the zero value (just expired or about to expire) is resolved.

\section{Conclusions}

The Infrastructure Value Index (IVI) is a well-known metric, widely applied in the world and is quickly becoming a standard to assess the state of water services infrastructure.

The Infrastructure Degradation Index (IDI) is a complementary metric that indicates the urgency to renovate the network. The IDI is measured in years, and presents a linear behaviour as the infrastructure deteriorates, while IVI behaves in a more asymptotic manner.

The IVI addresses the depreciation or investment aspects of the infrastructure, while the IDI is focused on the time that service managers may have before the state of the infrastructure becomes critical.

The combination of IVI and IDI values provides a deeper understanding of the state of a network than the use of IVI alone. However, two single metrics are not enough to provide an in-depth analysis of the situation.

The Infrastructure Histogram $\left(\mathrm{H}_{\mathrm{I}}\right)$ presents much more significant information than the IVI and the IDI combined, although it lacks the simplicity of single metrics. 
The $\mathrm{H}_{\mathrm{I}}$ allows analysing the current state of the network, the renovation policy undertaken in the past and the renovation rate required in the future.

Information-wise, the usefulness of IDI compared to $\mathrm{H}_{\mathrm{I}}$ may be questionable, as it includes all the information that IDI expresses and much more. However, it is slightly more difficult to produce and, conceptually, IDI may be the perfect companion to IVI. The tool to be used in each situation should be determined by convenience and target audience.

The authors were able to reach similar conclusions with the study of IVI, IDI and $\mathrm{H}_{\mathrm{I}}$ than by studying the full dataset. Additionally, the analysis of IDI and $\mathrm{H}_{\mathrm{I}}$ provided greater insight to the actual situation of the assets than the use of IVI alone. In any case, these tools are only as accurate as the data used to feed them are, and therefore are strongly dependent on the quality of pipe records and the accuracy of life expectancy values.

\section{Acknowledgements}

The authors would like to acknowledge Baseform Labs for supplying real data used in this paper.

\section{References}

AEAS-AGA (Asociación Española de abastecimientos de agua y saneamiento Asociación Española de empresas gestoras de los servicios de agua urbana). 2017. Ejercicio sobre infraestructuras hidráulicas. Aproximación al inventario de infraestructuras, precio actual y renovación anual (borrador). [Exercise on hydraulic infrastructures. Approach to infrastructure inventory, current price and annual renewal (draft)]. 
AEAS (Asociación Española de abastecimientos de agua y saneamiento). Forthcoming. Guía Técnica para la gestión de activos en redes de abastecimiento (borrador). [Technical guide for water supply networks asset management (draft)]. Aware-p.org. 2014. AWARE-P / Software. [online] Available at: http://www.awarep.org/np4/software/ [Accessed 25 Nov. 2018].

Baseform. 2018. Baseform. [online] Available at: https://baseform.com/np4/product [Accessed 24 Nov. 2018].

Alegre, Helena. 2008. Gestão Patrimonial de Infra-Estruturas de Abastecimento de Água e de Drenagem e Tratamento de Águas Residuais. [Infrastructure Asset Management of water, sewerage and wastewater services] Lisbon: LNEC. doi:978-972-49-2134-1.

Alegre, Helena, Rita Brito, and Dídia Covas. 2015. Tactical Planning of Urban Water Services at Utility Level TRUST Manual of Best Practice, Vol. 4. https://riunet.upv.es/handle/10251/54105.

Alegre, Helena, and Dídia Covas. 2010. Guia Técnico 16. Gestão Patrimonial de InfraEstruturas de Abastecimento de Água. Uma Abordagem Centrada Na Reabilitação. [Technical guide 16: Infrastructure Asset Management of water services. An approach focused in rehabilitation] Edited by Entidade Reguladora dos Serviços de Águas e Resíduos (ERSAR), Laboratório Nacional de Engenharia Civil (LNEC), and Instituto Superior Técnico (IST). Lisbon. doi:304814/10.

Alegre, Helena, and Dídia Covas. 2015. Integrated Planning of Urban Water Services: A Global Approach. TRUST Manual of Best Practice, Vol. 1. http://hdl.handle.net/10251/53758.

Alegre, Helena, Diogo Vitorino, and Sergio Coelho. 2014. "Infrastructure Value Index: A Powerful Modelling Tool for Combined Long-Term Planning of Linear and 
Vertical Assets.” Procedia Engineering 89. Elsevier B.V.: 1428-36.

doi:10.1016/j.proeng.2014.11.469.

Almeida, Maria do Céu, Dídia Covas, and Paula Beceiro. 2015. Rehabilitation of Sewers and Manholes: Technologies and Operational Practices. TRUST Manual of Best Practice, Vol. 6. http://hdl.handle.net/10251/54143.

Amaral, Rita, Helena Alegre, and J. S. Matos. 2016. “A Service-Oriented Approach to Assessing the Infrastructure Value Index." Water Science and Technology 72 (2): 542-48. doi:10.2166/wst.2016.250

ASCE (American Society of Civil Engineers). 2011. Failure to Act: The Economic Impact of Current Investment Trends in Water and Wastewater Treatment Infrastructure.

http://www.asce.org/uploadedFiles/Infrastructure/Failure_to_Act/energy_report_F INAL2.pdf.

AWWA (American Water Works Association). 2001. Dawn of the Replacement Era Reinvesting in Drinking Water Infrastructure. Vol. 80235. Washington, USA. www.awwa.org.

AWWA (American Water Works Association). 2012. Buried No Longer: Confronting America's Water Infrastructure Challenge. Washington, USA. www.awwa.org. Baptista, Jaime Melo. 2014. The Regulation of Water and Waste Services. 1st ed. London.

Boudreau, S.;, and D. Brynildsen. 2003. "National Guide to Sustainable Municipal Infrastructure." Newsletter of the Municipal Engineers Division 6 (1): 1-2.

Cabrera Jr., Enrique ; 2016. “The Need for the Regulation of Water Services. Key Factors Involved." In Regulation of Urban Water Services. An Overview. ISBN: 9781780408170 
Canal de Isabel II Gestión. 2012. Normas Para Redes de Abastecimiento. [Standards for water supply networks] https://www.canalgestion.es/es/galeria_ficheros/pie/normativa/normativa/Normas _redes_abastecimiento2012_CYIIG.pdf.

CSA (Castalia Strategic Advisors). 2014. Exploring the Issues Facing New Zealand's Water, Wastewater and Stormwater Sector. Wellington, New Zeeland.

Covas, D., Cabral, M., Pinheiro, A., Marchionni, V., Antunes, S., Lopes, N., Mamouros, L., Brôco, N.. 2018. Guia Técnico 23. Custos de construção de infraestruturas associadas ao ciclo urbano da agua.. IST and ERSAR. Lisbon

Frost \& Sullivan. 2011. Western European Water and Wastewater Utilities Market. https://store.frost.com/western-european-water-and-wastewater-utilitiesmarket.html\#section1.

GWRC (Global Water Research Coalition). 2009. Compendium of Best Practices in Water Infrastructure Asset Management. Australia. Edited by J. Bhagwan. Global Water Research Coalition, London

IPWEA (Institute Public Works Engineering Australasia). 2015. International Infrastructure Management Manual (IIMM). 5th ed. IPWEA, Institute Public Works Engineering Australasia. https://www.ipwea.org/publications/ipweabookshop/iimm.

ISO (International Organization for Standardization). 2016. Annex B ISO 24516 Guidelines for the management of assets of water supply and wastewater systems - Part 1: Drinking water distribution networks. International Organization for Standardization, Genebra.

ISO (International Organization for Standardization). 2014a. ISO 55000 Asset management - Overview, principles and terminology. International Organization 
for Standardization, Genebra.

ISO (International Organization for Standardization). 2014b. ISO 55001 Asset management - Management systems: Requirements. International Organization for Standardization, Genebra.

ISO (International Organization for Standardization). 2014c. ISO 55002 Asset management - Management systems: Guidelines for the application of ISO 55001. International Organization for Standardization, Genebra.

Leitão, João P, Sérgio T Coelho, Helena Alegre, Maria A Cardoso, S Maria, Pedro Ramalho, Rita Ribeiro, et al. 2016. "Moving Urban Water Infrastructure Asset Management from Science into Practice.” Urban Water Journal 13 (2). Taylor Francis: 133-41. doi:10.1080/1573062X.2014.939092.

Marchionni, Valentina, MArta Cabral, Conceicao Amado, and Dídia Covas. 2015. “Estimating Water Supply Infrastructure Cost Using Regression Techniques." Water Resources Planning and Management 142 (4). doi:10.1061/(ASCE)WR.1943-5452.0000627.

Marchionni, Valentina, Nuno Lopes, Luis Mamouros, and Dídia Covas. 2014. “Modelling Sewer Systems Costs with Multiple Linear Regression.” Water Resources Management 28 (13): 4415-31. doi:10.1007/s11269-014-0759-z.

Nottarp-heim, Dominik, Wolf Merkel, Helena Alegre, Andreas Hein, and Aine Gormley. 2015. Transition to Sustainable Urban Water Services of Tomorrow: A Handbook for Policy Makers. TRUST Manual of Best Practice, Vol. 2. https://riunet.upv.es/handle/10251/49396.

Pulido-Veláquez, Manuel, Enrique Cabrera, and Alberto Garrido. 2014. “Economía Del Agua y Gestión de Recursos Hídricos.” Ingeniería Del Agua 18 (1): 99-110. doi:10.4995/ia.2014.3160. 
Rokstad, Marius Møller, Rita Maria Ugarelli, and Sveinung Sægrov. 2016. "Improving Data Collection Strategies and Infrastructure Asset Management Tool Utilisation through Cost Benefit Considerations.” Urban Water Journal 13 (7). Taylor Francis: 710-26. doi:10.1080/1573062X.2015.1024692.

van Heck, Geert Jan. 2008. “Asset Management Frameworks for (Drinking Water) Infrastructures around the World: A (Not Exhaustive) Overview of Different Initiatives and Developments." In 2008 First International Conference on Infrastructure Systems and Services: Building Networks for a Brighter Future (INFRA), 1-6. IEEE. doi:10.1109/INFRA.2008.5439626. 


\section{Tables with captions}

Table 5. IVI and IDI values of Networks 1, 2 and 3. Values calculated for year 2019

\begin{tabular}{|l|l|l|l|}
\hline & Network 1 & Network 2 & Network 3 \\
\hline $\begin{array}{l}\text { Year of installation (45\% of the network } \\
\text { length) }\end{array}$ & 1967 & 1942 & 1994 \\
\hline $\begin{array}{l}\text { Year of installation (55\% of the network } \\
\text { length) }\end{array}$ & 2012 & 2012 & 1994 \\
\hline IVI & 0.5 & 0.5 & 0.5 \\
\hline IDI (years) & 23 & 12 & 25 \\
\hline
\end{tabular}


Table 6 Life expectancy and percentage of materials used in the case study networks

\begin{tabular}{|c|c|c|c|c|c|c|}
\hline & $\begin{array}{l}\text { Ductile } \\
\text { iron }\end{array}$ & $\begin{array}{l}\text { Asbestos } \\
\text { Cement }\end{array}$ & $\begin{array}{c}\text { Polyethylene } \\
\text { (PE) }\end{array}$ & $\begin{array}{c}\text { Polyvinylchloride } \\
\text { (PVC) }\end{array}$ & Steel & Concrete \\
\hline $\begin{array}{l}\text { Life } \\
\text { expectancy }\end{array}$ & 70 & 50 & 50 & 50 & 70 & 70 \\
\hline Network 1 & $70 \%$ & $7 \%$ & $20 \%$ & $0 \%$ & $1 \%$ & $3 \%$ \\
\hline Network 2 & $46 \%$ & $35 \%$ & $20 \%$ & $3 \%$ & $0 \%$ & $0 \%$ \\
\hline Network 3 & $3 \%$ & $20 \%$ & $45 \%$ & $30 \%$ & $2 \%$ & $0 \%$ \\
\hline Network 4 & $5 \%$ & $9 \%$ & $50 \%$ & $35 \%$ & $1 \%$ & $0 \%$ \\
\hline Network 5 & $1 \%$ & $42 \%$ & $54 \%$ & $1 \%$ & $2 \%$ & $0 \%$ \\
\hline Network 6 & $37 \%$ & $5 \%$ & $52 \%$ & $1 \%$ & $3 \%$ & $2 \%$ \\
\hline Network 7 & $95 \%$ & $0 \%$ & $5 \%$ & $0 \%$ & $0 \%$ & $0 \%$ \\
\hline Network 8 & $55 \%$ & $33 \%$ & $0 \%$ & $0 \%$ & $2 \%$ & $9 \%$ \\
\hline
\end{tabular}


Table 7: IDI and IVI results for each network

\begin{tabular}{|c|c|c|}
\hline & IDI (years) & IVI \\
\hline Network 1 & 37.00 & 0.57 \\
\hline Network 2 & 38.23 & 0.64 \\
\hline Network 3 & 26.57 & 0.51 \\
\hline Network 4 & 30.76 & 0.58 \\
\hline Network 5 & 16.34 & 0.34 \\
\hline Network 6 & 34.04 & 0.52 \\
\hline Network 7 & 22.69 & 0.32 \\
\hline Network 8 & 19.68 & 0.35 \\
\hline
\end{tabular}


Table 8: Comparison of similar networks

\begin{tabular}{|c|c|c|c|}
\hline & IDI (years) & IVI & $\begin{array}{c}\text { Preferred } \\
\text { network }\end{array}$ \\
\hline Network 1 & 37.00 & 0.57 & \\
\hline Network 2 & 38.23 & $\mathbf{0 . 6 4}$ & $\mathbf{X}$ \\
\hline Network 1 & $\mathbf{3 7 . 0 0}$ & 0.57 & $\mathbf{X}$ \\
\hline Network 4 & 30.76 & 0.58 & \\
\hline Network 3 & 26.57 & 0.51 & \\
\hline Network 6 & $\mathbf{3 4 . 0 4}$ & 0.52 & $\mathbf{X}$ \\
\hline Network 5 & 16.34 & 0.34 & \\
\hline Network 7 & $\mathbf{2 2 . 6 9}$ & 0.32 & $\mathbf{X}$ \\
\hline Network 7 & $\mathbf{2 2 . 6 9}$ & 0.32 & $?$ \\
\hline Network 8 & $\mathbf{1 9 . 6 8}$ & 0.35 & $\mathbf{?}$ \\
\hline
\end{tabular}




\section{Figures}

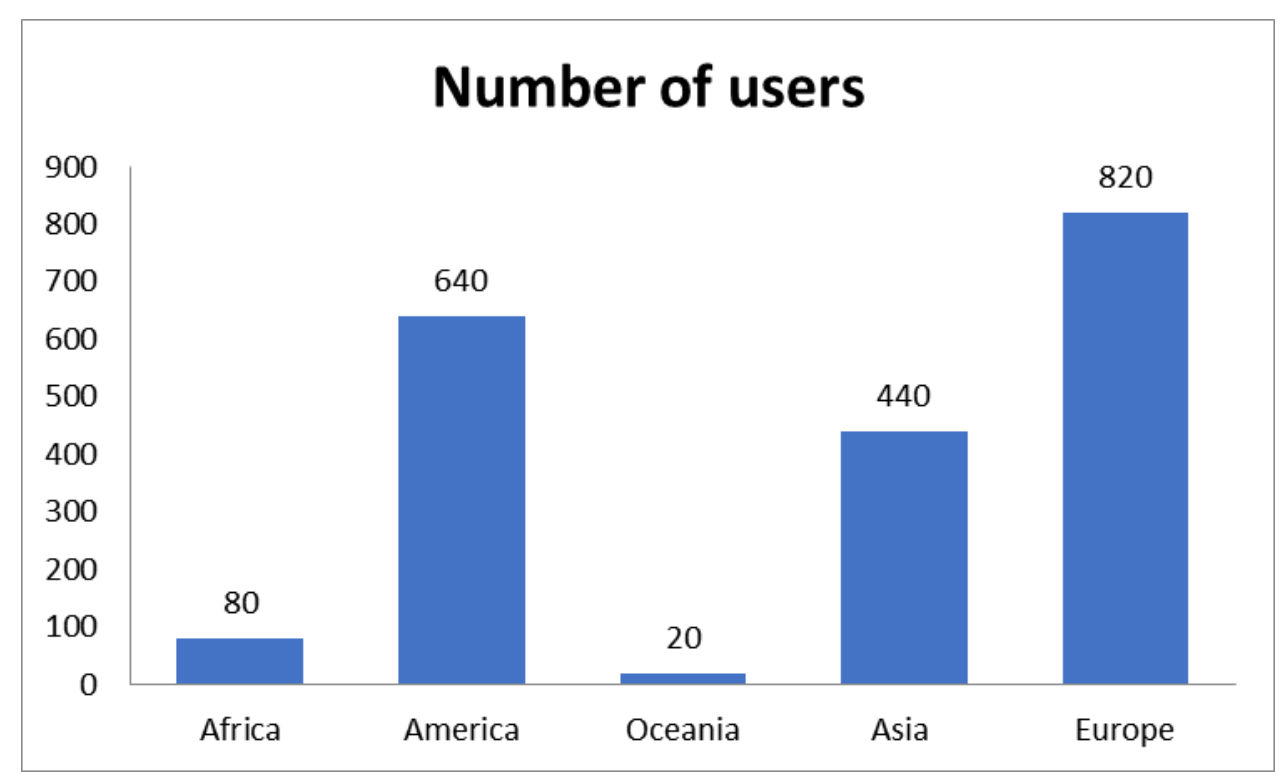

Figure 1. Geographical distribution of Aware-P software users making use of the IVI (AWARE-P users' database).

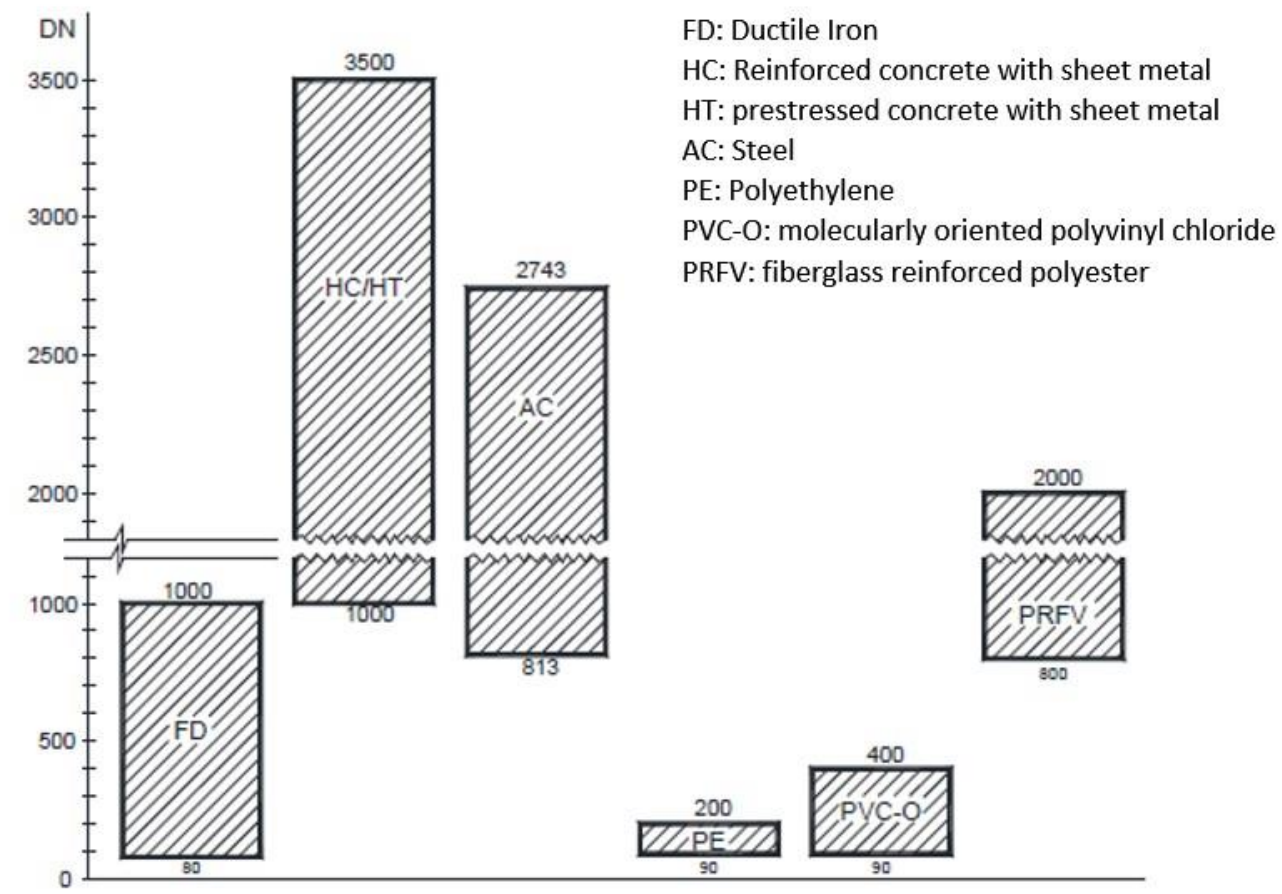

Figure 7: Standard materials used for pipe renovation by nominal diameter ( $\mathrm{DN}$ in $\mathrm{mm}$ )

- Madrid (Spain) - Canal de Isabel II - Adapted 


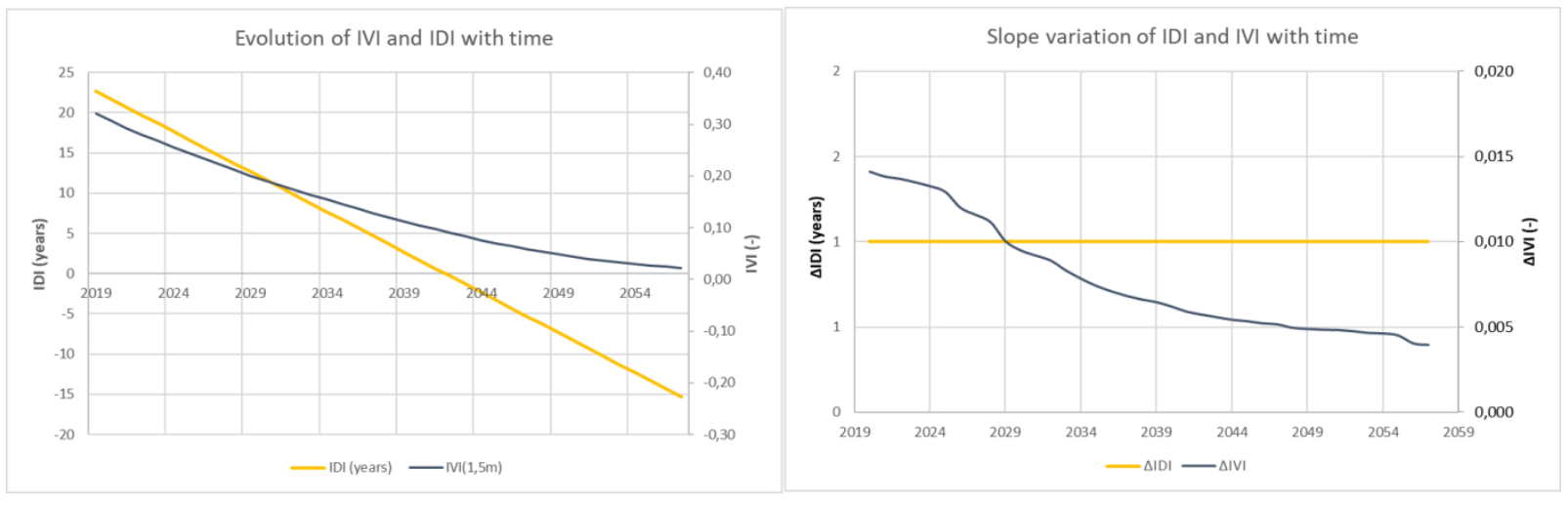

Figure 3. (1) Evolution of IVI and IDI with time. (2) Slope variation of IDI and IVI with time. Analysis of network 8, (Table 3) from 2019 to 2057, considering no renovation is undertaken in the network

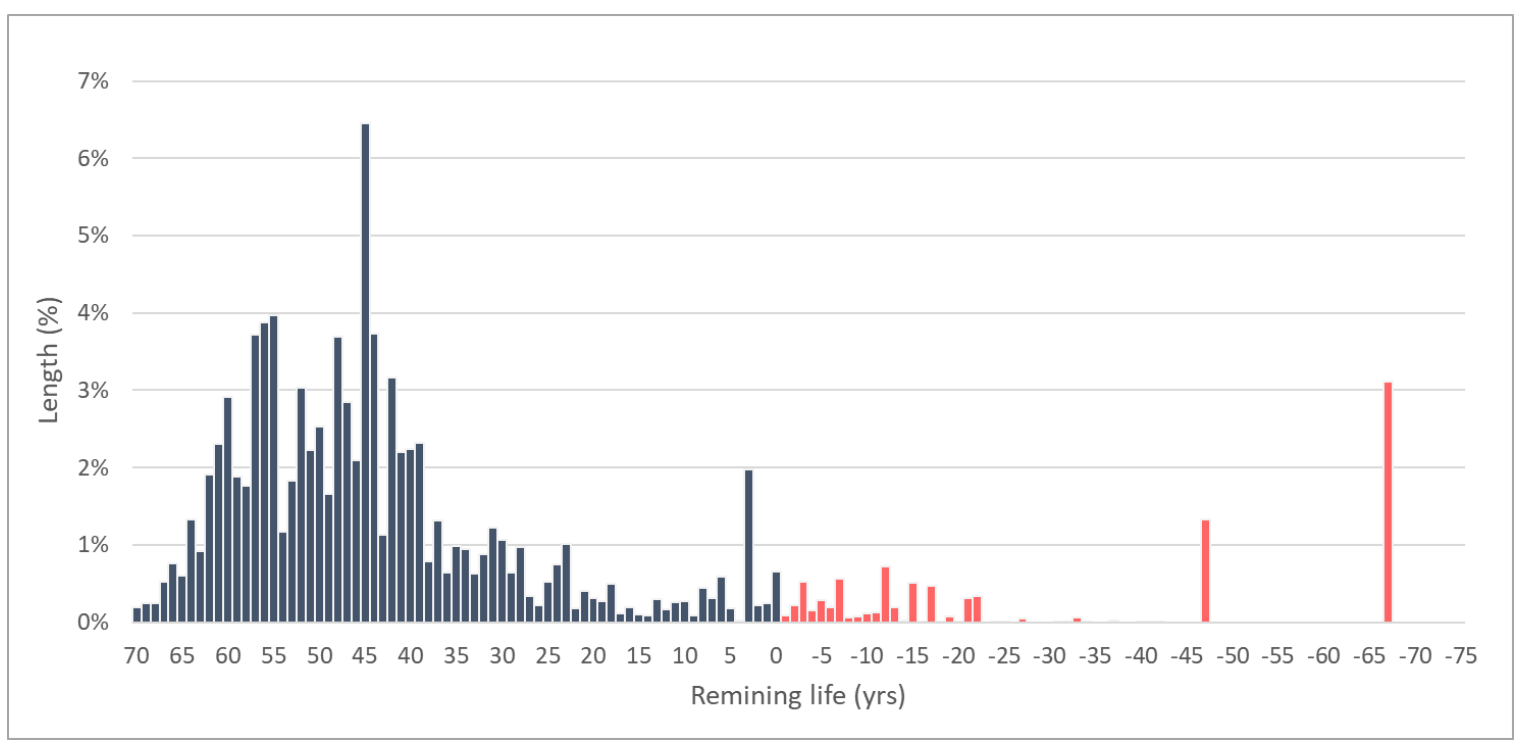

Figure 4. Example of a histogram for a water supply network

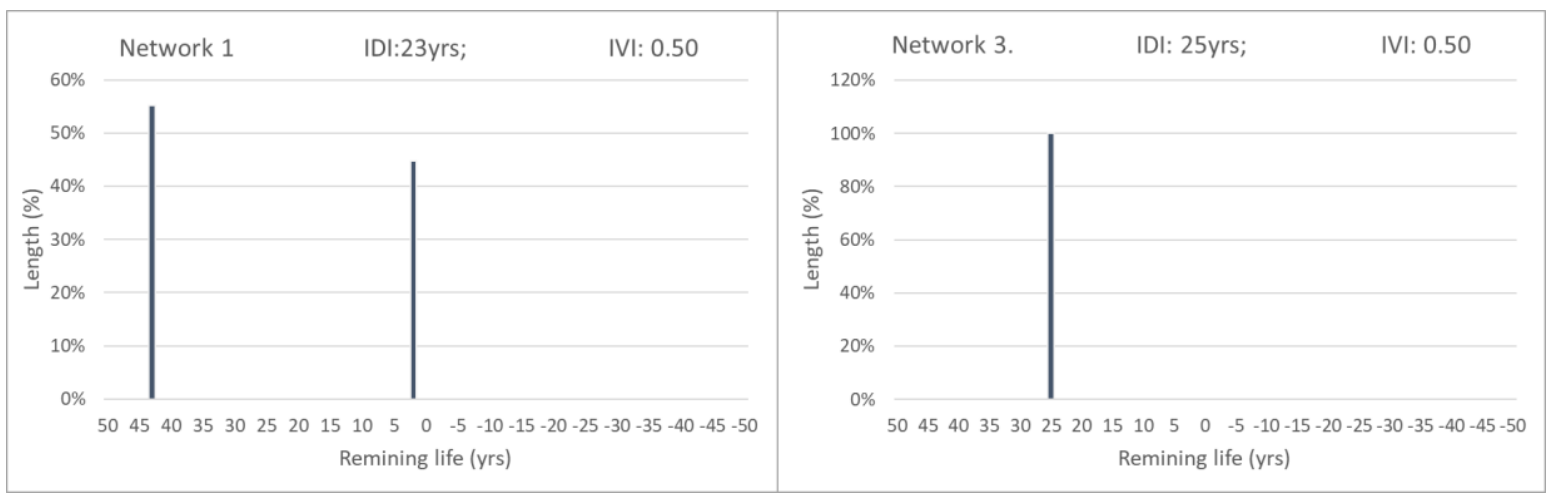

Figure 5. Histogram of Networks 1 and 3 presented in Table 1 


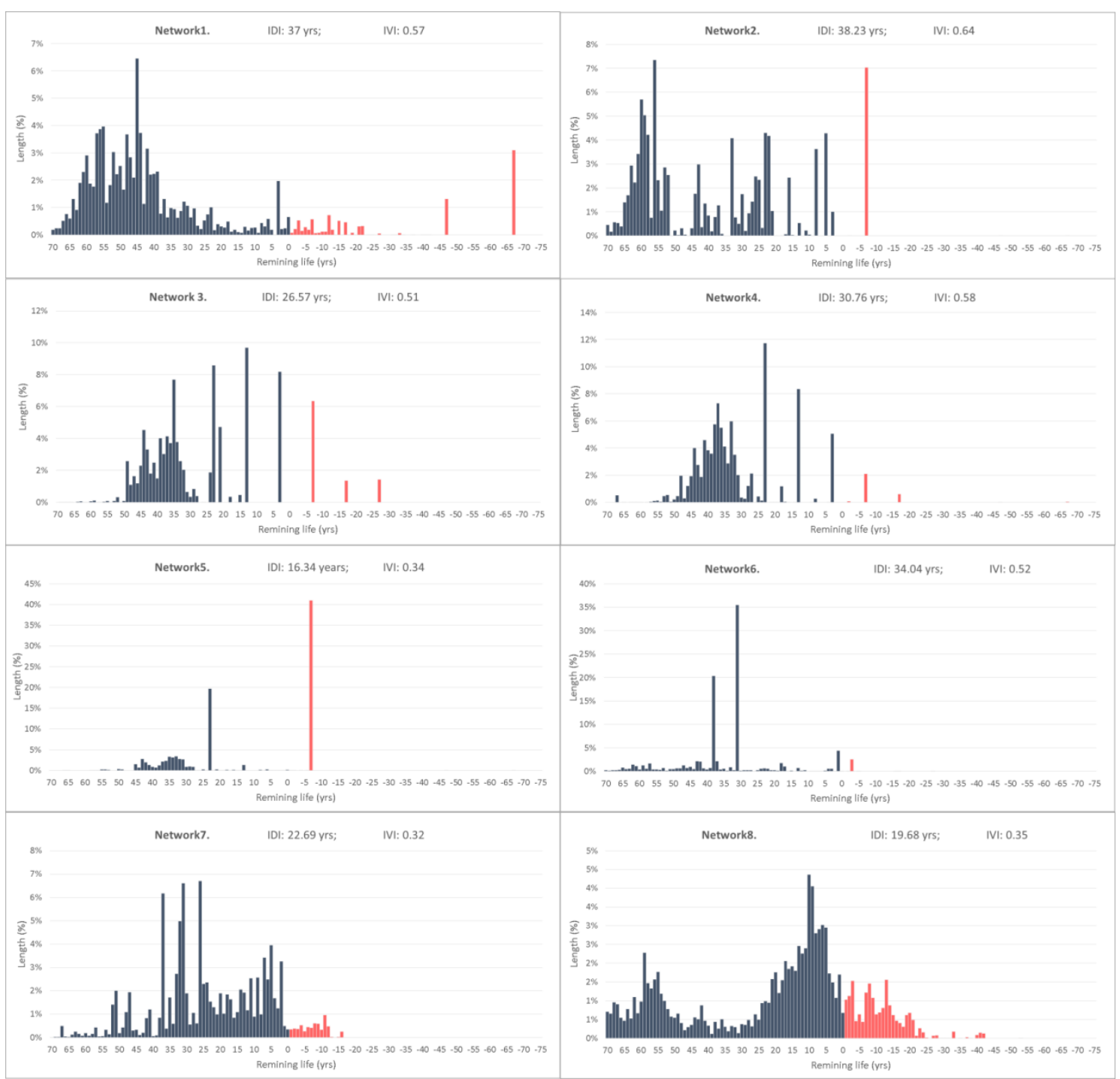




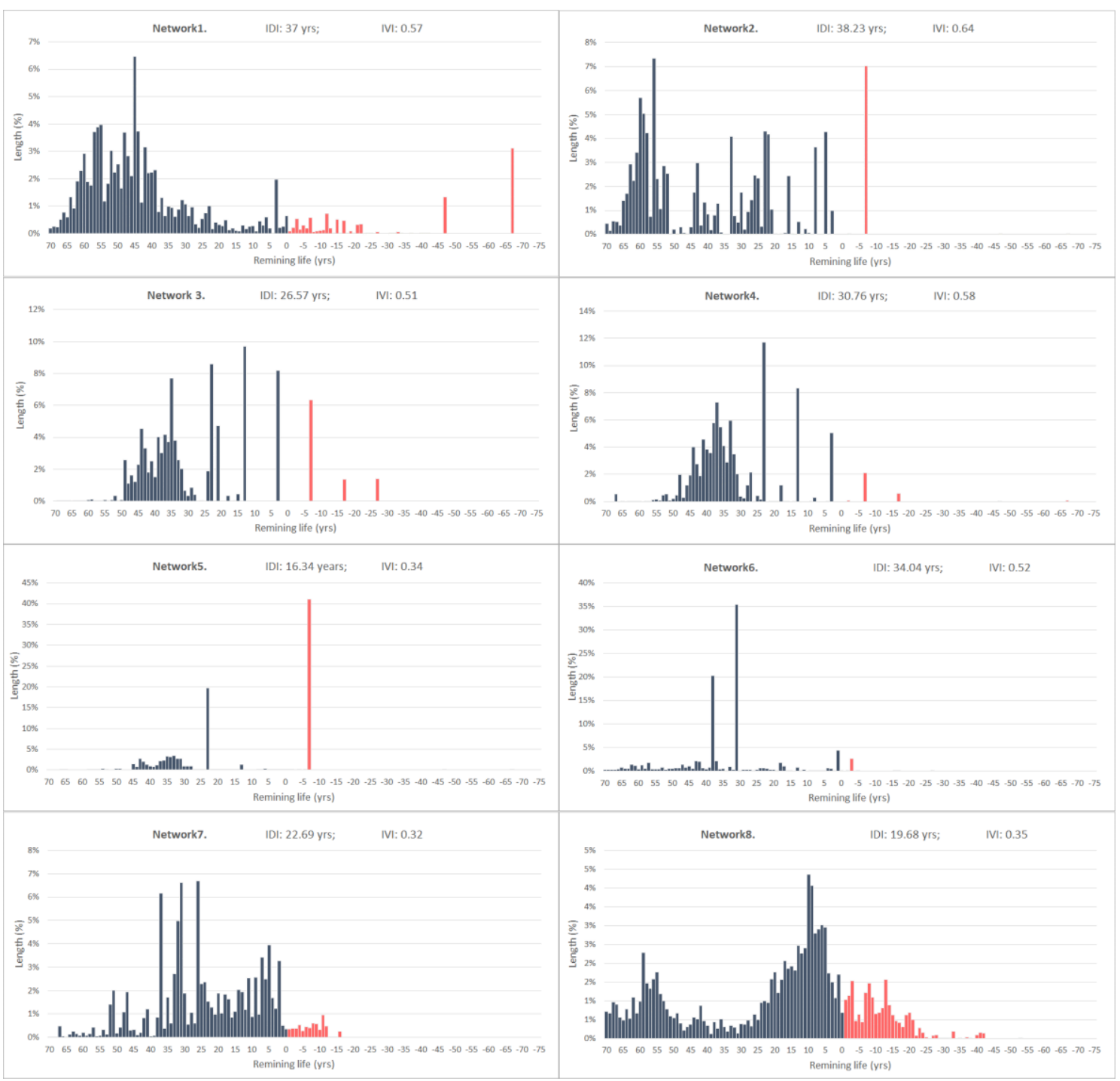

Figure 6. Histogram for the 8 case study networks 


\section{Figure captions}

Figure 1. Geographical distribution of Aware-P software users making use of the IVI (AWARE-P users' database).

Figure 2: Pipe renovation policy for Madrid (Spain) - Canal de Isabel II - Adapted

Figure 3. (1) Evolution of IVI and IDI with time. (2) Slope variation of IDI and IVI with time. Analysis of network 8, (Table 3) from 2019 to 2057, considering no renovation is undertaken in the network

Figure 4. Example of a histogram for a water supply network

Figure 5. Histogram of Networks 1 and 3 presented in Table 1

Figure 6. Histogram for the 8 case study networks 